\title{
The Maximum-Tolerated Dose and
}

\section{Pharmacokinetics of a Novel Chemically Modified Curcumin in Rats}

\author{
Heta Dinesh Bhatt $\mathbb{D}^{\prime}$, Steve A McClain², Hsi-Ming Lee', Thomas Zimmerman $\mathbb{D}^{3}$, Jie Deng $\mathbb{D}^{4}$, \\ Francis Johnson $\mathbb{D}^{5}$, Ying $\mathrm{Gu}^{6}$, Lorne M Golub' \\ 'Department of Oral Biology and Pathology, School of Dental Medicine, Stony Brook University, Stony Brook, NY, II 794, USA; ${ }^{2}$ Department of \\ Dermatology and Department of Emergency Medicine, Stony Brook University, and McClain Laboratories LLC, Smithtown, NY, I I 787, USA; \\ ${ }^{3}$ Division of Laboratory Animal Resources (DLAR) at Stony Brook, Stony Brook University, Stony Brook, NY, II 794, USA; ${ }^{4}$ Department of \\ Orthodontics, School of Stomatology, Peking University, Beijing, People's Republic of China; ${ }^{5}$ Department of Chemistry and Pharmacological Sciences, \\ School of Medicine, Stony Brook University, Stony Brook, NY, I I794, USA; 'Department of General Dentistry, School of Dental Medicine, Stony \\ Brook University, Stony Brook, NY, I I794, USA
}

Correspondence: Heta Dinesh Bhatt, Department of Oral Biology and Pathology, School of Dental Medicine, Stony Brook University, Stony Brook, NY, I I794, USA, Tel +I 646 7I5-2925, Fax + I 63I 632-9705, Email drhetabhatt@gmail.com

Purpose: CMC 2.24, a chemically modified curcumin, was developed as a novel, pleiotropic MMP-inhibitor to treat various inflammatory/collagenolytic diseases including periodontitis. To date, this compound has shown efficacy in vitro, in cell culture, and in vivo (oral administration) in mice, rats and dogs. In preparation for possible Phase I human clinical trials, the current study describes the maximum-tolerated-dose (MTD), pharmacokinetics (PK), and toxicology of CMC 2.24 in the rat model.

Methods: For the MTD study, 30 Sprague-Dawley rats were randomly distributed into 5 groups (3M/3F per group): Placebo (vehicle; carboxymethylcellulose) and CMC 2.24 at various doses $(50,100,500,1000 \mathrm{mg} / \mathrm{kg} /$ day $)$, were administered once daily by oral gavage for 5 days. For the PK study, 24 rats were administered either Placebo or CMC $2.24(100 \mathrm{mg} / \mathrm{kg} / \mathrm{day})$ once daily for 28 days or only once $(500$ or $1000 \mathrm{mg} / \mathrm{kg}$ ). Analysis of this test compound was done using LC/MS/MS for PK evaluation on blood samples drawn from rats at multiple time points. The animals were sacrificed after 5 or 28 days of treatment, and blood chemistry and serology were analyzed. Major organs (heart, lung, liver, kidney, spleen, intestine, brain) were histologically examined at necropsy.

Results: Orally administered, CMC 2.24 did not produce significant changes in body weight, food consumption or adverse events in the MTD and toxicology studies. Moreover, no obvious pathologic changes were observed based on histology, hematology, serum biochemistry, or necropsy compared to placebo-treated controls. The PK study demonstrated a peak-blood concentration $\left(\mathrm{C}_{\max }\right)$ at 45 mins after oral administration of 2.24 and a serum half-life of 10 hours.

Conclusion: In conclusion, CMC 2.24, orally administered to rats once a day, appears to be safe and effective at a wide range of doses, consistent with efficacy previously demonstrated in studies on animal models of various collagenolytic diseases, such as periodontitis, diabetes and cancer.

Keywords: novel compound, MMP-inhibitor, oral administration, toxicology

\section{Introduction}

Periodontitis is the 6 th most common disease affecting $11 \%$ of the world's population. ${ }^{1}$ This chronic inflammatory condition is characterized by destruction of the collagen-rich, tooth-supporting structures (in addition to the gingiva) including the cementum, periodontal ligament fibers, and alveolar bone. However, it is initiated by the dental microbial biofilm which is comprised of anaerobic gram-negative bacteria such as Porphyromonas gingivalis and Tannerella forsythia, which releases cell wall constituents notably lipopolysaccharide (LPS, endotoxin). ${ }^{2-4}$ The consequence of this unbalanced host response is the destruction and loss of periodontal connective tissues including alveolar bone. ${ }^{5-9}$ The mechanisms involved include excessive local production of pro-inflammatory mediators (primarily cytokines, 
chemokines, prostanoids, and reactive oxygen species) as well as connective tissue-destructive enzymes, notably the matrix metalloproteinases (MMPs), which result in the extensive soft tissue and bone breakdown characteristics of periodontitis. ${ }^{10}$ In essence, periodontitis occurs not as a result of a bacterial infection in the classical sense, but rather as a consequence of a polymicrobial disruption of the host-response homeostasis. ${ }^{8,9,11,12}$

As reviewed by Giannobile, ${ }^{13}$ research on the protective effects of common non-steroidal anti-inflammatory drugs (NSAIDs), resolvins (omega-3 fatty acids), and previously unrecognized non-antimicrobial properties of tetracyclines led to the concept of host modulation as an effective therapy for arresting periodontitis progression. ${ }^{14}$ The rationale behind using host modulation therapy (HMT) involves restoring the balance between, on the one hand, the pro-inflammatory mediators and destructive enzymes, and, on the other hand, the anti-inflammatory mediators and enzyme inhibitors. ${ }^{8,13-17}$ With this background in mind, the emergence of HMT using pharmaceutical/biologic agents as an adjunct to traditional mechanical treatment (scaling and root planing combined with effective oral hygiene measures) to reduce the microbial biofilm, also serves to break the vicious cycle between local and systemic inflammation. ${ }^{18}$

There have been many therapies that act by reducing the microbial burden in the periodontal pockets, including mechanical removal of plaque and calculus by scaling and root planing and use of antimicrobial mouth rinses or topical agents. However, to date, there is only one US-FDA and other national regulatory agency (Europe and Canada)-approved host modulation therapy, and this therapy is based on the surprising nonantimicrobial properties of the tetracycline antibiotics. ${ }^{8,14-17}$ This and other host modulation therapies focus on modifying or reducing the pro-inflammatory responses of the immune cells while upregulating the anti-inflammatory component of the host response. ${ }^{17,18}$ Recently, a new HMT has been proposed, which is based on a common dietary product, curcumin [1,7-bis-(4-hydroxy-3methoxyphenyl)-1,6-heptadiene-3,5-dione], a natural dietary ingredient of turmeric. Curcumin is the bis-vinyl homologue of Bis-aroyl methanes (BAMs) and possesses a $\beta$-diketone assembly responsible for the metal-ion binding property similar to that found in the tetracyclines. ${ }^{19,20}$ Curcumin appears to have a wide range of activities including both biological and pharmacological activities. ${ }^{21}$ Its therapeutic use, however, has been limited due to poor oral bioavailability and low solubility. This eventually led to the development of 30 structural analogues of curcumin (polyenolic zincbinding agents) by our group, and selection of a lead compound, CMC2.24 (as described below), which has been characterized by greater bioactivity, improved solubility, and no evidence of toxicity even at high doses. ${ }^{19,20,22-24}$

This novel compound, chemically modified curcumin 2.24 (CMC2.24) is a phenylamino carbonyl curcumin, which is tri-ketonic (enhancing its zinc-binding characteristics) in contrast to the diketonic active site on both the tetracyclines and on traditional/natural curcumin compounds. It has shown evidence of efficacy in vitro, in cell and organ culture, and in animal models of chronic inflammatory and other diseases. ${ }^{19,20,22-28} \mathrm{CMC} 2.24$ also exhibits improved solubility and greater zinc-binding capability than curcumin, and enhanced biological activity as an inhibitor of inflammatory chemokines, cytokines, and zinc- and calcium-dependent MMPs, such as the collagenases and gelatinases. ${ }^{19,20}$ CMC2.24 attenuates pathologically elevated levels of pro-inflammatory cytokines and MMPs in vivo, ${ }^{22,23}$ in vitro, ${ }^{19,20}$ and in cell culture, induced either locally (periodontitis; 1st "hit") or systemically (diabetes, 2nd "hit") with preliminary evidence of resolvin-enhancing activity. These unique characteristics indicate that $\mathrm{CMC} 2.24$ could be a novel therapeutic compound for the treatment and management of periodontitis and other inflammatory-collagenolytic diseases.

However, in order to develop CMC2.24 into a clinically useful medication, its toxicity (or lack thereof) and pharmacokinetics in animals has to be investigated. Thus, the current study was designed to determine a) the maximum tolerated dose (MTD) and toxicity of CMC2.24 following oral administration of various doses ranging from $50 \mathrm{mg} / \mathrm{kg} /$ day to $1000 \mathrm{mg} / \mathrm{kg} / \mathrm{day}$, and b) to evaluate its pharmacokinetics (PK) following daily oral dosing (gavage) in both male and female Sprague-Dawley (SD) rats. Two types of pharmacokinetics studies were carried out: (1) a long-term pharmacokinetic study carried over a period of 28 days following oral administration of $100 \mathrm{mg} / \mathrm{kg} /$ day of CMC2.24, and (2) a single dose pharmacokinetic study in which a single oral dose of either $500 \mathrm{mg} / \mathrm{kg}$ or $1000 \mathrm{mg} / \mathrm{kg}$ of CMC2.24 was administered to both male and female Sprague-Dawley (SD) rats. The results from these studies demonstrated that CMC2.24 is safe at doses as high as $1000 \mathrm{mg} / \mathrm{kg} /$ day in rats. The study described below characterizes the toxicity, safety, and pharmacokinetics of $\mathrm{CMC} 2.24$, and supports its development as a potential oral medication following appropriate human clinical trials. 


\section{Materials and Methods \\ Animals \\ MTD Study}

Eight- to twelve-week-old Sprague-Dawley (SD) rats (Strain code: CD001, Body Weight/Age: 276-300 grams/60-65 days; viral antibody free; Charles River Laboratories International, Inc., Wilmington, MA, USA) were randomly assigned to vehicle-treated controls and CMC2.24-treated dose groups as follows: one placebo-treated control group (vehicle alone; carboxymethylcellulose) and four multiple-dose groups of CMC $2.24(50,100,500,1000 \mathrm{mg} / \mathrm{kg} / \mathrm{day}$ suspended in the vehicle). The rats ( 3 males +3 females per group) in these groups were orally administered the placebo or treatment once daily for 5 days. After assignment to the different experimental groups, there were no significant body weight differences between the groups. Animals were group-housed in solid bottom polycarbonate cages ( 3 animals/cage) and provided with pelleted food and water ad-libitum unless otherwise specified. The environmental controls for the animal room were set to maintain $20-25^{\circ} \mathrm{C}$, a relative humidity of $50-70 \%$, a minimum of 10 air changes $/ \mathrm{h}$, and a 12 -h light $/ 12$ $\mathrm{h}$ dark cycle (except that the light/dark cycle might be interrupted for study-related activities).

\section{Pharmacokinetic (PK) Study}

(a) Long-term pharmacokinetic study: Twelve six- to eight-week-old Sprague-Dawley (SD) (250-350 grams) rats were purchased from Charles River and randomly distributed into placebo treated controls and CMC 2.24 treated groups. Placebos were orally administered carboxymethylcellulose and treatment group given a dose of $100 \mathrm{mg} /$ kg per day orally administered for 28 days. There were three males and three females per group. Animals were maintained as described above.

(b) Single dose pharmacokinetic study: Twelve six- to eight-week-old twelve Sprague-Dawley (SD) rats were purchased from Charles River and randomly distributed into two CMC 2.24 treated groups. There were three males and three females per group $(n=6)$. The rats in each of the two groups were administered a single oral dose of CMC2.24 at either $500 \mathrm{mg} / \mathrm{kg}$ or $1000 \mathrm{mg} / \mathrm{kg}$ immediately before collecting the blood at various time points (for pharmacokinetic analysis) over a period of 24 hours.

Blood samples were collected for both the long-term and single-dose pharmacokinetic studies at the end of the study at 5 mins, 15 mins, 45 mins, $1 \mathrm{hr}, 2 \mathrm{hr}, 4 \mathrm{hr}, 6 \mathrm{hr}$ and $24 \mathrm{hrs}$ after oral administration of vehicle or CMC2.24 to analyze at the pharmacokinetics of the drug CMC2.24.

The numbers of animals, study design, and treatment of animals were reviewed and approved by the Institutional Animal Care and Use Committee (IACUC, IACUC\#: 230617-26). All procedures in this protocol are following the US Department of Agriculture's (USDA) Animal Welfare Act.

\section{Placebo and Treatment}

(A) Placebo: The placebo vehicle was 2\% carboxymethylcellulose obtained from Sigma, Lot number $87 \mathrm{H} 0036$ and administered by oral gavage.

(B) Chemically Modified Curcumin 2.24 (CMC 2.24): The compound was provided by Chem-Master Intl. Inc. ( $99.5 \%$ pure, Stony Brook, NY, USA) and was suspended using polytron in vehicle, carboxymethylcellulose, at different concentrations for the different dosage groups.

\section{Study Design MTD Study}

Fifteen female and fifteen male SD rats were randomly distributed into placebo and treatment groups. The placebo group was administered $2 \%$ carboxymethylcellulose by oral gavage once daily. The treatment groups were administered, by oral gavage, CMC 2.24 at $50 \mathrm{mg} / \mathrm{kg}, 100 \mathrm{mg} / \mathrm{kg}, 500 \mathrm{mg} / \mathrm{kg}$ and $1000 \mathrm{mg} / \mathrm{kg}$ per day for 5 days. The MTD in this study was defined by Robinson et $\mathrm{al}^{29}$ as the highest dose that will be tolerated and not produce major life-threatening toxicity for the study duration. Previous studies have shown the doses of this compound, ranging from $1 \mathrm{mg} / \mathrm{kg} / \mathrm{day}$ to $30 \mathrm{mg} / \mathrm{kg} /$ day to be safe and efficacious in various in vivo and in vitro models. ${ }^{23-28,30,31}$ Hence, the starting dose for the MTD study 
was selected to be $50 \mathrm{mg} / \mathrm{kg} /$ day and above in order to determine the maximum dose that can be tolerated, or a dose at which toxicity is observed. ${ }^{30}$ At the end of 5 days, the body weight, daily food consumption, hematology, and serum biochemistry were evaluated. The postmortem evaluation included gross examination of all the animals at the terminal necropsy, as well as histopathological examination of major organs, kidney, liver, lungs, heart, colon and spleen in the control and high-dose groups. Hematology and clinical chemistry were tested at termination of the protocol.

\section{Pharmacokinetic Study}

a) Steady state pharmacokinetics: Six male and six female SD rats were randomly distributed into the placebo and control groups. While the control group was administered a vehicle of $2 \%$ carboxymethylcellulose, the treatment group was given CMC 2.24 at the dose of $100 \mathrm{mg} / \mathrm{kg}$ per day, all by oral gavage. A previous preliminary study of pharmacokinetics in vivo $(500 \mathrm{mg} / \mathrm{kg}$ by oral route and $20 \mathrm{mg} / \mathrm{kg}$ by intravenous (i.v.) route) showed poor bioavailability of the CMC2.24 based on blood analysis. ${ }^{31}$ Though the dose of $500 \mathrm{mg} / \mathrm{kg}$ showed poor bioavailability, it involved a single dose pharmacokinetic study and blood was analyzed only at 2 and 6 hours. Therefore, this study was designed for a period of 28 days at an oral dose of $100 \mathrm{mg} / \mathrm{kg} /$ day to determine more accurately steady state pharmacokinetics. At the end of the study, blood was drawn at 5 mins, 10 mins, 15 mins, 30 mins, 45 mins, 1 hour, 2 hour, 4 hour, 6 hours and at 24 hours for analysis. The pharmacokinetic parameters analyzed were half-life $\left(t_{1 / 2}\right)$, time taken to reach maximum concentration $\left(\mathrm{T}_{\max }\right)$, and maximum concentration in blood $\left(\mathrm{C}_{\max }\right)$. We also evaluated body weight, daily food consumption, hematology, and serum biochemistry. The postmortem evaluation included gross examination of all the animals at the terminal necropsy and histopathological examination of major organs - kidney, liver, lungs, heart, colon and spleen - in the control and high-dose groups. Hematology and clinical chemistry were tested at termination.

b) Single-dose pharmacokinetics: Twelve SD rats, 6 males and 6 females were distributed into two groups of $500 \mathrm{mg} / \mathrm{kg}$ and $1000 \mathrm{mg} / \mathrm{kg}$. Each rat was administered a single oral gavage of CMC 2.24, and blood was drawn at $5 \mathrm{mins}, 10 \mathrm{mins}, 15$ mins, 30 mins, 45 mins, 1 hour, 2 hour, 4 hour, 6 hours and at 24 hours. No other tissue or organ (except blood) was collected at various time points. The blood collected was sent for LC/MS/MS evaluation.

\section{Termination \\ MTD Study}

On day 5, all the animals were euthanized, and necropsy was performed on each. End point body weight was recorded and gross examination of major organs - heart, lungs, liver, kidney, spleen, and colon - was done followed by histopathologic analysis. Blood plasma and serum were collected for hematologic and serologic analysis.

\section{Pharmacokinetic Study}

For the long-term pharmacokinetic study, on the 28th day, all the animals were anesthetized, and their body weight was recorded. After that, blood was collected at multiple time points $-5 \mathrm{~min}, 15 \mathrm{mins}, 45 \mathrm{mins}, 1$ hour, 2 hours, 4 hours, 6 hours, and 24 hours. After 24-hour time-period, blood samples were collected for hematological and serological analysis, necropsy was performed and gross examination of major organs - heart, lungs, liver, kidney, spleen, and colon - was done; then, the organs were collected for histopathologic analysis. For the single dose pharmacokinetic study, blood was drawn at 5 mins, 10 mins, 15 mins, 30 mins, 45 mins, 1 hour, 2 hours, 4 hours, 6 hours and at 24 hours, and plasma was used to analyze half-life $\left(t_{1 / 2}\right)$, maximum plasma time $\left(\mathrm{T}_{\max }\right)$, and concentration $\left(\mathrm{C}_{\max }\right)$. No other tissue or organ except blood was collected at these various time points. The blood collected was sent to the Proteomics center (Stony Brook University, NY, USA) for pharmacokinetic evaluation.

\section{Pharmacokinetics (PK)}

Liquid Chromatography Mass Spectrometry/Mass Spectrometry (LC/MS/MS) was performed using a Thermo TSQ Quantum Access (Thermo-Fisher) Triple Quadrupole Mass Spectrometer at the Proteomics Center (Health Sciences Tower, Stony Brook University, NY, USA). Chromatographic separation was performed on Aquasil C18 column, with water and acetonitrile (ACN) at $200 \mathrm{ul} / \mathrm{min}$. Detection was carried out using multiple reaction monitoring (MRM) $\mathrm{m} / \mathrm{z}$ $426>262$ and $426>289$ (confirmation ion) using electrospray ionization in negative ion mode. Samples were prepared 
as follows: $50 \mathrm{ul}$ sample $+150 \mathrm{uACN}$ and the precipitated proteins removed by centrifugation. Then, $50 \mathrm{ul}$ supernatant was mixed with $50 \mathrm{ul}$ water and $10 \mathrm{ul}$ injected for analysis.

\section{Histopathological Examination}

After sacrificing the animals, the following organs were dissected and examined: heart, lungs, liver, kidney, spleen, and colon. These tissues were processed after fixation with formalin, alcohol dehydration, xylene cleaning and paraffin embedding. Hematoxylin and eosin sections were prepared at 5-micron size and examined by conventional microscopy using a BX 61 Olympus. These sections were then imaged using Olympus DP 71 digital camera. All the sections were scored by a board-certified pathologist, Dr. Steve McClain, MD (Department of Pathology, Stony Brook University of Medicine, NY, USA), who was blinded to the study.

\section{Statistical Evaluation}

For both the MTD and pharmacokinetic study, data from the control group and dose groups were analyzed using the Student's $t$-test. The significance was set at $<0.05$ with two tailed probability levels.

\section{Results}

\section{Body Weight and Adverse Events}

For the Maximum Tolerated Dose Study (MTD), we first determine the lethal dose or maximum tolerated dose of CMC 2.24 in $30 \mathrm{SD}$ rats by orally administering doses of $50,100,500$ and $1000 \mathrm{mg} / \mathrm{kg} /$ day for 5 days. No mortality was observed in the treatment groups during the period of 5 days even at the highest dose. Mean body weight (Figure 1A), observed for both sexes during the 5 days, did not show significant differences from the placebo treated controls. Daily food consumption as well as adverse events showed no difference over the period of 5 days for both sexes (data not shown).

For the pharmacokinetics study, twelve SD rats were distributed into placebo-treated control (vehicle only) and treatment groups $(100 \mathrm{mg} / \mathrm{kg} /$ day of CMC 2.24) administered orally for 28 days. Both sexes showed no significant differences in the mean body weight (Figure 1B) compared to the placebo treated controls at any of the doses tested. Similarly, no adverse events were reported for any of the rats during the period of 28 days at a dose of $100 \mathrm{mg} / \mathrm{kg} / \mathrm{day}$.

\section{Histopathologic Changes Observed in the Tissue from Control and CMC2.24 Treated Rats}

Gross examination of the organs for both the studies showed no abnormalities in any organ. For the MTD study, the H\&E staining of tissue sections (Figure 2A and 2B) observed in the heart, lungs, liver, kidney, spleen, and colon showed no morphologic changes at increasing doses of CMC $2.24(50,100,500,1000 \mathrm{mg} / \mathrm{kg} /$ day $)$ compared to the placebo-treated controls. Also, for the pharmacokinetic study, over 28 days at a dose of $100 \mathrm{mg} / \mathrm{kg} / \mathrm{day}$, the H\&E tissue sections (Figure $2 \mathrm{~B}$ and $2 \mathrm{~A}$ ) showed no clinically significant histologic changes when compared to the placebo-treated controls.

Various parameters were analyzed for each of the following organs: a) heart: single or multiple foci of red eosinophilic fibers, necrosis, inflammatory infiltrate, fibrosis, endocardium and valves; b) lungs: congestion, bronchi, necrosis, fibrosis, inflammatory infiltrate; c) spleen: atrophy, extra-medullary hematopoiesis, changes in red and white pulp; d) liver: inflammatory infiltrate, necrosis, fibrosis, hepatocellular vacuolization; e) colon: atrophy, ulceration, inflammatory infiltrate; and f) kidney: proteinaceous filtrate, fibrosis, inflammatory infiltrate. In summary, no cytotoxic changes were observed in both the studies in doses ranging from 50 to $1000 \mathrm{mg} / \mathrm{kg} /$ day dose in any tissue examined (Table 1).

\section{Hematologic and Serologic Parameters}

A number of parameters were examined by hematological analysis of the blood samples for both the MTD and pharmacokinetic studies (Tables 2 and 3).

Biochemical analysis of animal blood samples showed no significant difference in any parameters for $1000 \mathrm{mg} / \mathrm{kg} /$ day CMC2.24 when compared with placebo treated controls (Table 2). Potassium levels showed a significant difference between the control group compared to the $500 \mathrm{mg} / \mathrm{kg}$ group, but all these measurements were within the published 
A

Day 1 Day 5

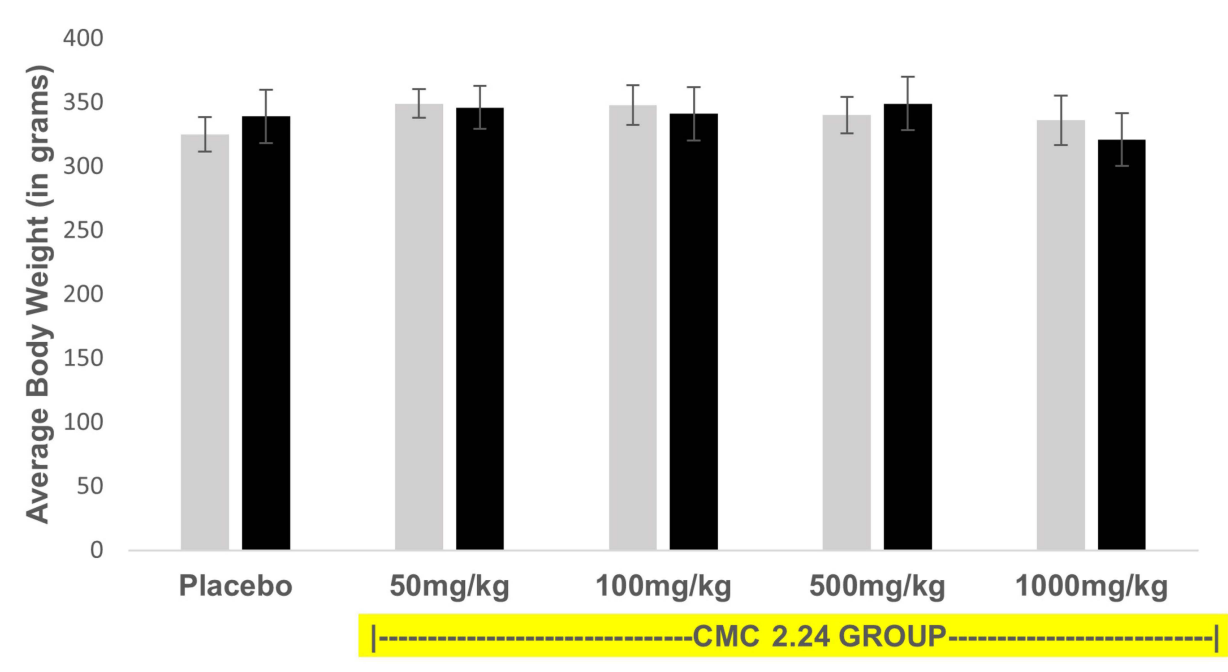

B

PLACEBO - CMC 2.24 (100mg/kg/day)

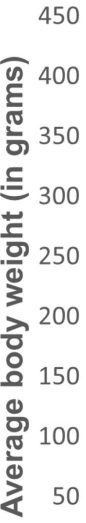

0

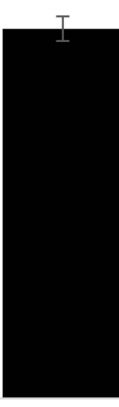

BODY WEIGHT (BASELINE)

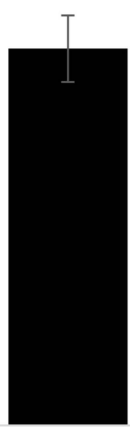

BODY WEIGHT (28 DAYS)

Figure I Average body weight of rats in a Maximum Tolerated Dose (MTD) and Pharmaco-kinetics (PK) Study of orally administered CMC 2.24 for 5 days and 28 days respectively. (A) The effect of orally administered CMC 2.24 (50, 100, 500, and $1000 \mathrm{mg} / \mathrm{kg} /$ day) on the body weight at base line and 5 days after starting CMC2.24 treatment at the time of sacrifice. It shows average body weight (g) in placebo/control and the CMC2.24-treated rats. Grey bar: Baseline for placebo and treatment groups; Black bar: Day 5 for normal and treatment groups Each value represents Mean ( $n=6 /$ group) \pm Standard Error Mean (S.E.M.). (B) The effect of orally administered CMC 2.24 (I00 mg/ $\mathrm{kg} /$ day) on the body weight at base line and 28 days after starting CMC2.24 treatment at the time of sacrifice. It shows average body weight ( $\mathrm{g}$ ) in placebo/control and the CMC2.24-treated rats. Grey bar: Baseline for normal and treatment groups; Black bar: Day 28 for placebo and treatment groups Each value represents Mean ( $\mathrm{n}=6 / \mathrm{group}) \pm$ Standard Error Mean (S.E.M.).

values for SD rats ${ }^{35}$ (https://www.criver.com/sites/default/files/resources/CDIGSRatModelInformationSheet.pdf). The highest dose group for the study $(1000 \mathrm{mg} / \mathrm{kg} /$ day $)$ showed no difference in any of the parameters tested. In the 28 day pharmacokinetic study, no significant differences were observed in any parameter for the CMC2.24 treated group when compared to the placebo treated controls (Table 3). Also, the values were compared with normal SD rat parameters and no significant differences were found (https://www.criver.com/sites/default/files/resources/ CDIGSRatModelInformationSheet.pdf) which confirmed that they are not out of the normal published range. ${ }^{35}$ 

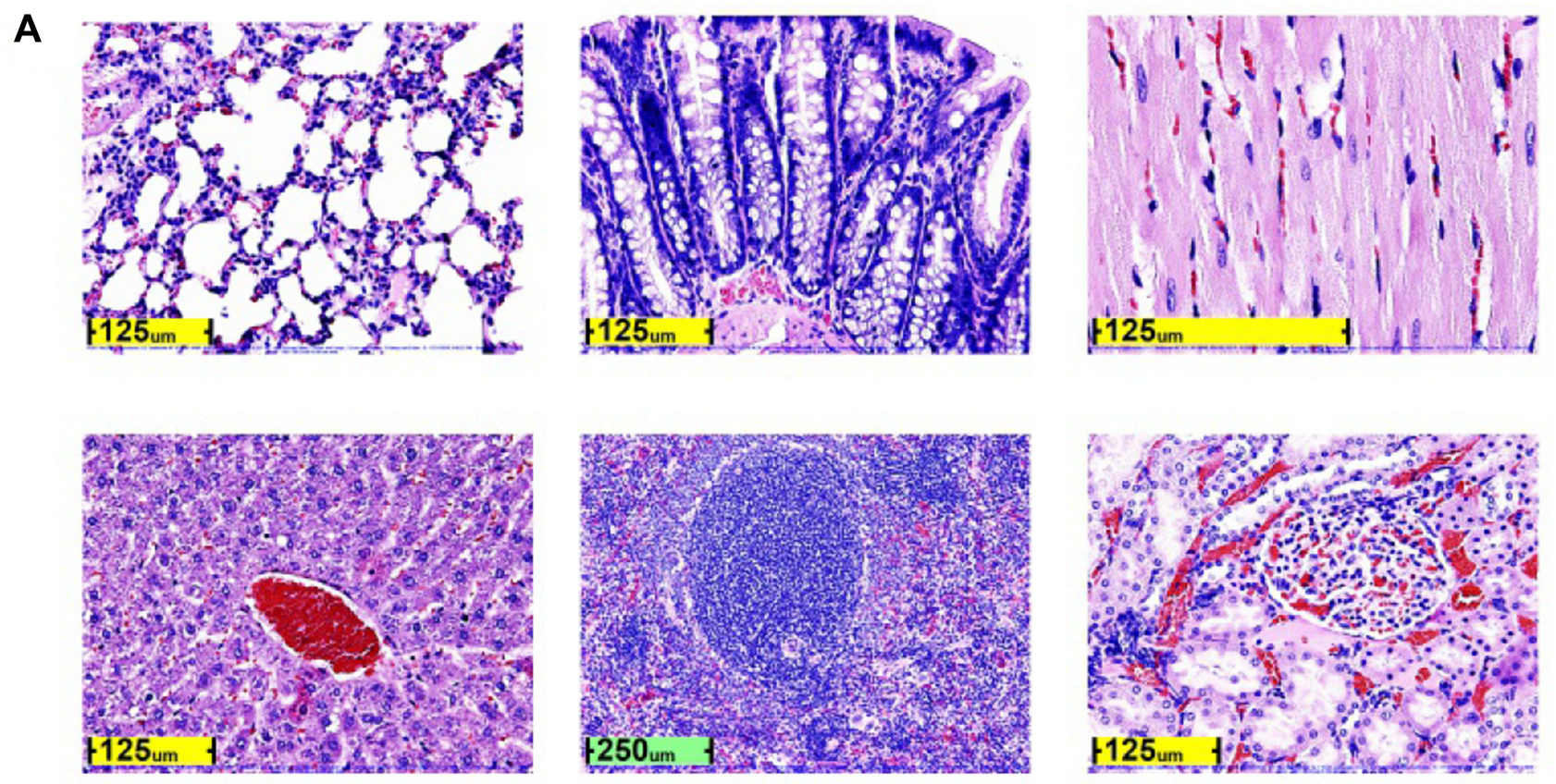

B
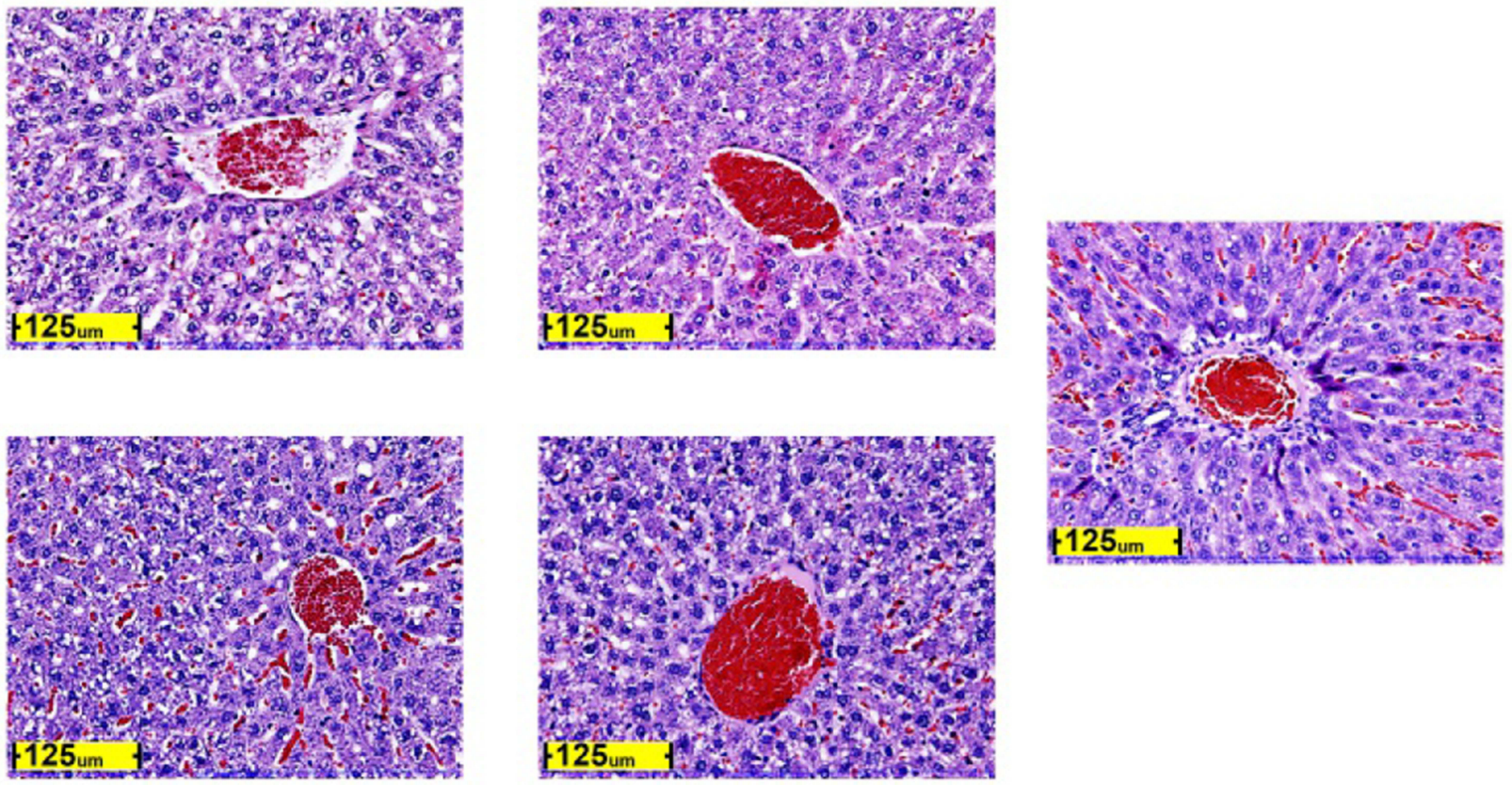

Figure 2 Effect of orally administered CMC2.24 on organs in Maximum Tolerated Dose (MTD) and Pharmaco-kinetics (PK) Study for 5 days and 28 days respectively. (A) The effect of orally administered CMC $2.24(50,100,500$, and $1000 \mathrm{mg} / \mathrm{kg} /$ day) on the organs (lung, colon, heart, kidney, spleen, and liver clockwise) at 5 days and 28 days after starting CMC2.24 treatment. It shows no acute pathological changes in the histology of CMC2.24-treated rats compared to controls. (B) The effect of orally administered CMC 2.24 (0,50, 1000, 100, and $500 \mathrm{mg} / \mathrm{kg} /$ day clockwise) on the liver at 5 days and 28 days after starting CMC2.24 treatment. At all doses up to $1000 \mathrm{mg} / \mathrm{kg} /$ day no evidence on cytotoxicity was observed in Liver or any other tissues examined (Lungs, Kidneys, Spleen, Colon, Heart) compared to the controls. All images shown here are representative of 883 images analyzed.

\section{Pharmacokinetics of CMC 2.24}

For the 28 days pharmacokinetic study, a peak blood concentration of $0.2 \mathrm{ng} / \mathrm{mL}$ of CMC2.24 $\left(\mathrm{C}_{\max }\right)$ at $100 \mathrm{mg} / \mathrm{kg} / \mathrm{day}$ was observed (Figure $3 \mathrm{~A}$ ) at 4 hours $\left(\mathrm{T}_{\max }\right)$. At all other time points, the concentration of $\mathrm{CMC} 2.24$ in blood was undetectable. In order to obtain more details about pharmacokinetics, single dose pharmacokinetic studies were carried out at doses of $500 \mathrm{mg} / \mathrm{kg}$ and $1000 \mathrm{mg} / \mathrm{kg}$. These results showed that the concentration of CMC2.24 peaked at $45 \mathrm{mins}$ 
Table I Summary of Histologic, Hematologic, and Serologic Parameters in Rats Treated with Various Doses in MTD and PK Study

\begin{tabular}{|c|c|c|}
\hline Parameters Scored & $\begin{array}{l}\text { 5-Day MTD Study (50, } 100 \\
500 \text { and } 1000 \mathrm{mg} / \mathrm{kg} / \mathrm{day})^{\mathrm{a}}\end{array}$ & $\begin{array}{l}\text { 28-Day PK Study } \\
(100 \mathrm{mg} / \mathrm{kg} / \text { day })^{\mathrm{a}}\end{array}$ \\
\hline Organs looked at (Heart, Lungs, Spleen, Liver, Kidney, Colon) & Normal Histology Observed & $\begin{array}{l}\text { Normal Histology } \\
\text { Observed }\end{array}$ \\
\hline $\begin{array}{l}\text { Hematological \& Serological parameters [Total protein, AST (SGOT), ALT (SGPT), } \\
\text { alkaline phosphatase, creatinine, Phosphorous (P), Glucose, Calcium (CA++), } \\
\text { Potassium (K), WBC, hematocrit] }\end{array}$ & No change observed & No change observed \\
\hline
\end{tabular}

Note: ${ }^{a}$ Compared to placebo-treated controls.

Abbreviations: MTD, maximum-tolerated-dose; PK, pharmacokinetics.

Table 2 Serum Chemistry, 5 Days MTD Study, Mean is Average of $n=6 \pm$ SD *p value $<0.05$

\begin{tabular}{|c|c|c|c|c|c|c|c|}
\hline \multirow[t]{2}{*}{ Parameters } & \multirow[t]{2}{*}{ Unit } & \multirow[b]{2}{*}{$\mathbf{N}$} & \multirow{2}{*}{$\begin{array}{c}\text { Control } \\
\text { Mean } \pm \text { SD }\end{array}$} & \multicolumn{4}{|c|}{ Chemically Modified Curcumin (CMC2.24) } \\
\hline & & & & $\begin{array}{c}\text { Mean } \pm \text { SD } \\
(50 \mathrm{mg} / \mathrm{kg} / \text { day })\end{array}$ & $\begin{array}{c}\text { Mean } \pm \text { SD } \\
(100 \mathrm{mg} / \mathrm{kg} / \text { day })\end{array}$ & $\begin{array}{c}\text { Mean } \pm \text { SD } \\
(500 \mathrm{mg} / \mathrm{kg} / \text { day })\end{array}$ & $\begin{array}{c}\text { Mean } \pm \text { SD } \\
(1000 \mathrm{mg} / \mathrm{kg} / \text { day })\end{array}$ \\
\hline Total protein & $g / d l$ & 6 & $7.1 \pm 0.36$ & $7.1 \pm 0.47$ & $7.1 \pm 0.59$ & $7.2 \pm 1.00$ & $6.8 \pm 0.74$ \\
\hline AST (SGOT) & $I U / I$ & 6 & $88.3 \pm 15.94$ & $94 \pm 23.41$ & $|46.7 \pm 9| .05$ & $96.7 \pm 35.98$ & $106.2 \pm 68.87$ \\
\hline ALT (SGPT) & $I U / I$ & 6 & $45.3 \pm 8.43$ & $43.3 \pm 11.7$ & $50.5 \pm 11.84$ & $50 \pm 19.56$ & $46.83 \pm 24.09$ \\
\hline Alkaline phosphatase & $I U / I$ & 6 & $233.2 \pm 89.71$ & $219.7 \pm 104.13$ & $235 \pm 125.58$ & $193.2 \pm 79.01$ & $164.8 \pm 75.11$ \\
\hline Creatinine & $I U / I$ & 6 & $0.43 \pm 0.05$ & $0.42 \pm 0.08$ & $0.42 \pm 0.04$ & $0.42 \pm 0.01$ & $0.4 \pm 0.06$ \\
\hline Phosphorous & $\mathrm{mg} / \mathrm{dl}$ & 6 & $12.07 \pm 1.54$ & $10.97 \pm 1.35$ & $10.97 \pm 2.15$ & $11.12 \pm 1.91$ & $11.6 \pm 2.47$ \\
\hline Glucose & $\mathrm{mg} / \mathrm{dl}$ & 6 & $195.2 \pm 29.93$ & $185.5 \pm 37.62$ & $213 \pm 70.16$ & $256.12 \pm 62.55$ & $246 \pm 73.10$ \\
\hline Calcium & $\mathrm{mg} / \mathrm{dl}$ & 6 & $12.7 \pm 0.35$ & $12.58 \pm 0.72$ & $12.07 \pm 0.96$ & $13.2 \pm 1.11$ & $12.7 \pm 0.77$ \\
\hline Potassium & $\mathrm{meg} / \mathrm{l}$ & 6 & $7.5 \pm 0.59$ & $8.2 \pm 0.6$ & $7.5 \pm 1.06$ & $8.3 \pm 0.54 *$ & $6.6 \pm 3.07$ \\
\hline WBC & $10^{3} / \mathrm{ul}$ & 6 & $10.6 \pm 3.64$ & $9.7 \pm 2.52$ & $9.03 \pm 2.52$ & $10.25 \pm 1.59$ & $7.4 \pm 1.99$ \\
\hline Hematocrit & $\%$ & 6 & $51.5 \pm 1.64$ & $52.3 \pm 3.5$ & $52.3 \pm 3.50$ & $52.5 \pm 2.51$ & $52.5 \pm 6.41$ \\
\hline
\end{tabular}

Abbreviation: SD, Standard Deviation.

( $\mathrm{T}_{\max }$ ) in the blood to $8 \mathrm{ng} / \mathrm{mL}\left(\mathrm{C}_{\max }\right)$ for the $500 \mathrm{mg} / \mathrm{kg}$ group (Figure 3B) and $6.7 \mathrm{ng} / \mathrm{mL}\left(\mathrm{C}_{\max }\right)$ for the $1000 \mathrm{mg} / \mathrm{kg}$ group (Figure 3C) which were essentially the same. However, in the $1000 \mathrm{mg} / \mathrm{kg}$ group, the compound was present at much higher levels at 24 hours than the blood levels observed for the $500 \mathrm{mg} / \mathrm{kg}$ group. The serum half-life of CMC2.24 from this study was determined to be 10 hours.

\section{Discussion}

These MTD and toxicology studies were performed to assess the safety and pharmacokinetic profile of the novel pleiotropic compound $\mathrm{CMC} 2.24$ following oral administration, for adult rats, at various doses. This novel compound CMC 2.24 has shown evidence of therapeutic potential in a number of studies using various in vitro, cell and organ culture, and animal models of chronic diseases, eg, periodontitis, diabetes, cancer, and so on. ${ }^{23,26-28,30-33}$

The MTD study was performed at 5 dose levels $(0=$ control, $50,100,500$ and $1000 \mathrm{mg} / \mathrm{kg} / \mathrm{day})$ of CMC2.24 administered daily orally for 5 days, and different parameters, such as mortality, body weight, food consumption, clinical pathology, and gross pathology, were examined during and/or at termination of the study. Both the body weight (Figure 1A) and food consumption (data not shown) showed no significant changes in placebo and CMC2.24 treated groups over a period of 5 days. The pharmacokinetic study was done for a period of 28 days with placebo 
Table 3 Serum Chemistry, 28 Days PK Study, Mean is Average of $n=2 / 6 \pm$ SD

\begin{tabular}{|c|c|c|c|}
\hline \multirow[t]{2}{*}{ Parameters } & \multirow[t]{2}{*}{ Unit } & Control (0 mg/kg/day) & CMC2.24 (100 mg/kg/day) \\
\hline & & Mean $(n=2) \pm S D$ & Mean $(n=6) \pm S D$ \\
\hline Total protein & $g / d l$ & $7.25 \pm 0.92$ & $6.83 \pm 0.72$ \\
\hline AST (SGOT) & $\mathrm{IU} / \mathrm{I}$ & $93.5 \pm 2.12$ & $110.17 \pm 49.6$ \\
\hline ALT (SGPT) & IU/I & $45 \pm 5.66$ & $61.7 \pm 28.2$ \\
\hline Alkaline phosphatase & $\mathrm{IU} / \mathrm{I}$ & $179 \pm 99$ & $139.8 \pm 80.62$ \\
\hline Creatinine & $\mathrm{IU} / \mathrm{I}$ & $0.45 \pm 0.07$ & $0.42 \pm 0.04$ \\
\hline Phosphorous & $\mathrm{mg} / \mathrm{dl}$ & $11.5 \pm 0.99$ & $11.15 \pm 0.8$ \\
\hline Glucose & $\mathrm{mg} / \mathrm{dl}$ & $227.5 \pm 72.8$ & $277.7 \pm 44.05$ \\
\hline Calcium & $\mathrm{mg} / \mathrm{dl}$ & $12.25 \pm 0.78$ & $12.27 \pm 0.52$ \\
\hline Potassium & meg/l & $8.35 \pm 0.35$ & $8.6 \pm 1.04$ \\
\hline WBC & $10^{3} / \mathrm{ul}$ & $7.6 \pm 3.82$ & $9.87 \pm 3.47$ \\
\hline Hematocrit & $\%$ & $50 \pm 5.66$ & $43.3 \pm 6.47$ \\
\hline
\end{tabular}

Abbreviation: SD, Standard Deviation.

(carboxymethylcellulose) and treatment group (CMC2.24 at $100 \mathrm{mg} / \mathrm{kg} / \mathrm{day})$. There was no significant change in the body weight (Figure 1B) over a period of 28 days when treated with CMC2.24. This shows that the treatment with various doses of CMC2.24 (up to $1000 \mathrm{mg} / \mathrm{kg}$ ) did not have any adverse effect on body weight or food consumption.

Major organs, such as heart, lung, liver, kidney, spleen, and colon, were collected for histopathology evaluation (Figure 2A and B). Various histologic parameters were analyzed in this study by a board-certified pathologist blinded to the study. No acute pathologic changes were seen in the MTD study up to $1000 \mathrm{mg} / \mathrm{kg} / \mathrm{day}$. No cytotoxicity or any acute histologic changes were detected in the pharmacokinetic study done for 28 days at $100 \mathrm{mg} / \mathrm{kg} / \mathrm{day}$ dose of CMC2.24. These toxicology studies demonstrated that $\mathrm{CMC} 2.24$ was a safe compound with one week of treatment at doses as high as $1000 \mathrm{mg} / \mathrm{kg}$. While we have not managed to demonstrate MTD in this study, the Food and Drug Administration (FDA) states that

in absence of MTD other equally appropriate limiting doses include those that achieve large exposure multiples or saturation of exposure or use the maximum feasible dose (MFD). (https://www.fda.gov/drugs/guidance-compliance-regulatory-information/ guidances-drugs)

Therefore, we have used $1000 \mathrm{mg} / \mathrm{kg} /$ day which is considered the high limit dose for acute, sub chronic, and chronic toxicity studies in rodents and non-rodents.

Our analysis of hematological and serological parameters such as urea nitrogen, ALT (alanine aminotransferase), AST (aspartate aminotransferase), and ALP (alkaline phosphatase), as well as histopathology, showed that CMC2.24 does not appear to be hepatotoxic or kidney toxic in rats at all the dose levels tested in the MTD study or in the 28 days pharmacokinetic study (Tables 2 and 3). Although potassium levels were significantly increased for the $500 \mathrm{mg} / \mathrm{kg}$ CMC2.24 group $(\mathrm{p}=0.029)$ compared to the placebo treated controls in MTD study, when compared with the published normal SD rat parameters they do not appear to be outside the normal range. ${ }^{35}$ Similarly, while the glucose levels are borderline increased for the $500 \mathrm{mg} / \mathrm{kg} \mathrm{CMC} 2.24$ treated group $(\mathrm{p}=0.057)$, compared to placebo treated controls, they are also not out of range when compared with the normal SD rat parameters provided on the website of the company from which rats were purchased. ${ }^{35}$ Also, the $1000 \mathrm{mg} / \mathrm{kg}$ (maximum dose) CMC2.24-treated group showed no significant differences in any parameters compared to control values. For the 28 days pharmacokinetic study, hematological and serological parameters of the CMC2.24 (100 mg/kg) treated groups were compared to only two control animals (one 

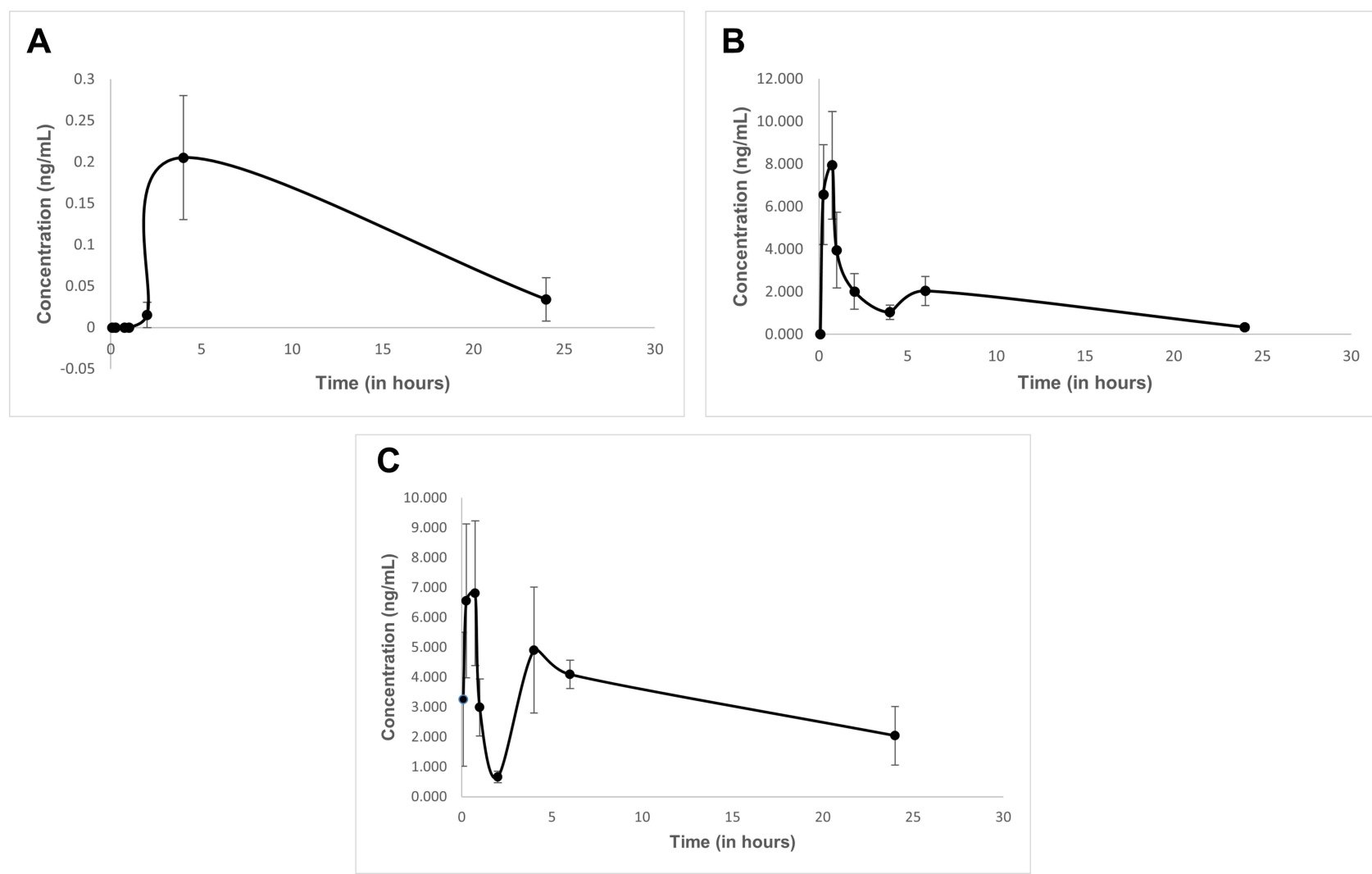

Figure 3 Effect of orally administered CMC2.24 on Pharmacokinetics (PK) in rat blood measured by LC/MS/MS. (A) The effect of orally administered CMC 2.24 (I00 mg/kg/ day) on the pharmacokinetics at 28 days after starting CMC2.24 treatment. The $C_{\max }$ seen here was at a very low level of $0.2 \mathrm{ng} / \mathrm{mL}$ at 4 hours. Each value represents Mean $(\mathrm{n}=6) \pm$ Standard Error Mean (S.E.M) at each time point. (B) The effect of orally administered CMC 2.24 on the pharmacokinetics after a single dose at $500 \mathrm{mg} / \mathrm{kg}$ of CMC2.24 treatment. The $C_{\max }$ seen here was at $8 \mathrm{ng} / \mathrm{mL}$ at 45 minutes. Each value represents Mean $(n=6) \pm$ Standard Error Mean (S.E.M) at each time point. (C) The effect of orally administered CMC 2.24 on the pharmacokinetics after a single dose at $1000 \mathrm{mg} / \mathrm{kg}$ of CMC2.24 treatment. The $C_{\max }$ seen here was at $6.7 \mathrm{ng} / \mathrm{mL}$ at $45 \mathrm{minutes}$. Each value represents Mean $(n=6) \pm$ Standard Error Mean (S.E.M) at each time point.

male and one female) since the toxicity study at that dose was already completed (Table 2). No significant difference was observed in any parameter when compared to the placebo treated controls (Table 3). These values were also compared with normal SD rat parameters available on a commercial website, which confirmed that they are not outside the normal range. ${ }^{35}$ Additionally, throughout the whole MTD study and 28 days pharmacokinetic studies, both groups of animals, control and CMC2.24-treated groups, were healthy, exhibiting no apparent changes in their behavior, food appetite and body weight. These results are, therefore, consistent with expectations that CMC2.24 is a potent and non-toxic MMPinhibitor, which also reduces inflammatory mediators and provides substantial evidence for the further evaluation of CMC2.24 as a potential promising therapy for human disease, which would depend on successful Phase I, II and III clinical trials.

The long-term pharmacokinetic study was done at one dose of $100 \mathrm{mg} / \mathrm{kg} /$ day administered once per day orally for a period of 28 days. Blood was collected at an interval of at $5 \mathrm{mins}, 10 \mathrm{mins}, 15 \mathrm{mins}, 30 \mathrm{mins}, 45 \mathrm{mins}, 1$ hour, 2 hours, 4 hours, 6 hours and at 24 hours for pharmacokinetic analysis. Since at this dose, $100 \mathrm{mg} / \mathrm{kg}$, the peak concentration of CMC2.24 was nearly undetectable $(0.2 \mathrm{ng} / \mathrm{mL})$, we then designed two single-dose pharmacokinetic studies. In a singledose pharmacokinetic study, SD rats were orally administered a single dose of $500 \mathrm{mg} / \mathrm{kg}$ or $1000 \mathrm{mg} / \mathrm{kg}$. For the single dose pharmacokinetic study, done at $500 \mathrm{mg} / \mathrm{kg}$ dose of CMC2.24, the $\mathrm{C}_{\max }$ was determined to be $8 \mathrm{ng} / \mathrm{mL}$ (Figure 3B) and for the $1000 \mathrm{mg} / \mathrm{kg}$ study the $\mathrm{C}_{\max }$ was $6.7 \mathrm{ng} / \mathrm{mL}$ (Figure 3C); a $\mathrm{T}_{\max }$ of $45 \mathrm{mins}$ was observed for both doses. In all three pharmacokinetic analyses, CMC2.24 was detected in the blood for up to 24 hours and the serum half-life of the drug was determined to be 10 hours.

Translating this novel pleiotropic compound, with excellent efficacy in vitro and in vivo, into an MMP-inhibitor drug for potential future human use, requires that it has appropriate pharmacological properties and is nontoxic to normal 
tissues and organs. To date, this compound has shown efficacy in vitro, cell culture, and in vivo (oral administration) in several species including mice, rats, and dogs. Most of our in vivo efficacy studies were carried out at either $10 \mathrm{mg} / \mathrm{kg}$ or $30 \mathrm{mg} / \mathrm{kg} .{ }^{22,23,26-28,34}$ A dose response study done for 28 days at doses $0,1,5,10$ and $30 \mathrm{mg} / \mathrm{kg}$ of body weight in rats showed that oral administration of $1 \mathrm{mg} / \mathrm{kg} /$ day of CMC2.24 is the minimum effective dose to significantly inhibit inflammation and alveolar bone resorption observed with the LPS-induced model of experimental periodontal disease. ${ }^{30}$ In a series of studies using different rat models of periodontal disease, including severely hyperglycemic diabetics, it was shown that orally administered CMC2.24 (30 mg/kg) reduces local and systemic inflammation and prevents hyperglycemia- and bacterial product (LPS)-associated, tissue destruction. ${ }^{22,23}$ In addition to the beneficial effects on periodontal disease, which was induced both locally (LPS injection) and systemically (eg, by diabetes), CMC2.24 treatment also favorably affected extra-oral connective tissues including skin and skeletal bone. ${ }^{23,28}$ Moreover, systemic treatment with CMC2.24 was found to inhibit NF- $\mathrm{kB}$ and p38 MAPK activation in both locally and systemically induced models of periodontitis. ${ }^{22}$ A recent study in the dog model of natural periodontitis, orally administered CMC2.24 (10 mg/ $\left.\mathrm{kg}\right)$, significantly decreased clinical measures of periodontitis, as well as suppressing inflammatory cytokines, MMPs, and cell-signaling molecules. These effects support its clinical potential as a novel adjunct to SRP in the treatment of chronic periodontitis. ${ }^{26}$ The effective doses of CMC2.24 used in these studies showed no evidence of toxicity in the animals used in these and previous studies. Taken together, all of these studies, including this report, demonstrate that effective doses of $10-30 \mathrm{mg} / \mathrm{kg}$, administered orally, are in the safe range for small (rodent) as well as large (dog) animals.

A preliminary in vivo pharmacokinetic study, using intravenous (i.v.) administration of $20 \mathrm{mg} / \mathrm{kg}$ was also carried out $^{31}$ (unpublished study by Zhang) which showed that CMC2.24 has considerably greater bioavailability in serum compared to curcumin. Upon analyzing the organs such as liver, heart, spleen, kidney, lungs, and brain, it was observed that CMC2.24 exhibits a significantly greater concentration, by a factor of 1.5 , in all the organs, compared to curcumin (unpublished data; Zhang). ${ }^{31}$ Pharmacokinetic studies of curcumin demonstrated that even at a high oral dose of $2 \mathrm{~g} / \mathrm{kg}$, it achieves a $C_{\max }$ of $1.35 \pm 0.23 \mu \mathrm{g} / \mathrm{mL}$ at 0.75 hours. ${ }^{36}$ Another study in humans by Lao et al demonstrated $\mathrm{C}_{\max }$ of curcumin in serum to be $50.5 \mathrm{ng} / \mathrm{mL}$ at 4 hours at an oral dose of $10 \mathrm{~g} / \mathrm{kg}$ and $57.6 \mathrm{ng} / \mathrm{mL}$ at 2 hours for an oral dose of $12 \mathrm{~g} / \mathrm{kg} .{ }^{37}$ In other studies, most of the pharmacokinetics of curcumin has been done with

the use of adjuvant like piperine that interferes with glucuronidation; second, the use of liposomal curcumin; third, curcumin nanoparticles; fourth, the use of curcumin phospholipid complex; and fifth, the use of structural analogues of curcumin

due to curcumin's poor absorption and bioavailability. ${ }^{38}$ All this information demonstrates that $\mathrm{CMC} 2.24$ has better bioavailability overall than curcumin. Most of our studies have used the oral route as a means of administering the drug to assess its efficacy and safety, which further supports its potential as a novel host-modulating therapeutic. Recent results indicated a half-life of 10 hours after oral administration makes the oral route a convenient, practical, and economically viable option for future clinical use. However, future studies need to be conducted to assess how the drug is metabolized as it moves through the digestive tract. The eventual therapeutic dosing of CMC2.24 and its optimized form of dosing will depend on additional future studies.

\section{Conclusion}

CMC 2.24 at multiple oral doses $(50,100,500,1000 \mathrm{mg} / \mathrm{kg} /$ day) produces no significant changes in body weight, food consumption, adverse events, or histopathology. Moreover, the hematological and serological analyses up to $1000 \mathrm{mg} / \mathrm{kg} /$ day showed no significant changes compared to placebo-treated control, demonstrating its safety at multiple oral doses in rats. These MTD, toxicology, and pharmacokinetic studies all support its potential applicability as an oral medication for future human use. Additional studies testing CMC2.24 safety and efficacy, in various models, are currently underway.

\section{Acknowledgments}

This study was supported by a CAT grant (Advanced Research and Development Center) from Stony Brook Univeristy, \& Traverse BioSciences Inc. I would like to thank Dr Steve McClain and McClain Laboratories LLC for their expertise and assistance in all the histology aspects of this manuscript. 


\section{Disclosure}

Lorne M. Golub is listed as an inventor on several related patents (20140275271, 20150073021, 20150150834, 20160213638, US 9675576B2), and these have been fully assigned to his institution, Stony Brook University, The State University of New York (SUNY). Francis Johnson is also listed as an inventor on several related patents (WO/2013/ 059203, 2014/0275271, 2015/0073021, 2015/0150834, 20160213638) which have been fully assigned to Stony Brook University and to Chem-Master Int. Inc. on a shared basis. In addition, both LMG and FJ are minor shareholders in Traverse BioSciences, Inc. All other authors declare that there are no conflicts of interest regarding the publication of this paper.

\section{References}

1. Kassebaum NJ, Bernabe E, Dahiya M, et al. Global burden of severe periodontitis in 1990-2010: a systematic review and meta-regression. $J$ Dent Res. 2014;93(11):1045-1053. doi:10.1177/0022034514552491

2. Kinane DF, Stathopoulou PG, Papapanou PN. Periodontal diseases. Nat Rev Dis Primers. 2017;3(1):17038. doi:10.1038/nrdp.2017.38

3. Feres M, Teles F, Teles R, Figueiredo LC, Faveri M. The subgingival periodontal microbiota of the aging mouth. Periodontol. 2000 2016;72(1):3053. doi:10.1111/prd.12136

4. Socransky SS, Haffajee AD, Cugini MA, Smith C, Kent RL Jr. Microbial complexes in subgingival plaque. J Clin Periodontol. 1998;25(2):134144. doi:10.1111/j.1600-051X.1998.tb02419.x

5. Evans RT, Klausen B, Ramamurthy NS, Golub LM, Sfintescu C, Genco RJ. Periodontopathic potential of two strains of Porphyromonas gingivalis in gnotobiotic rats. Arch Oral Biol. 1992;37(10):813-819. doi:10.1016/0003-9969(92)90115-O

6. Ryan ME. Host modulation: conceptualization to clinical trials and integration into clinical practice. J Calif Dent Assoc. 2002;30(4):285-8, 90-5.

7. Gitlin JM, Loftin CD. Cyclooxygenase-2 inhibition increases lipopolysaccharide-induced atherosclerosis in mice. Cardiovasc Res. 2009;81(2):400407. doi:10.1093/cvr/cvn286

8. Gu Y, Walker C, Ryan ME, Payne JB, Golub LM. Non-antibacterial tetracycline formulations: clinical applications in dentistry and medicine. $J$ Oral Microbiol. 2012;4(1):19227. doi:10.3402/jom.v4i0.19227

9. Van Dyke TE. Commentary: periodontitis is characterized by an immuno-inflammatory host-mediated destruction of bone and connective tissues that support the teeth. J Periodontol. 2014;85(4):509-511. doi:10.1902/jop.2014.130701

10. Corbella S, Francetti L, Taschieri S, De Siena F, Fabbro MD. Effect of periodontal treatment on glycemic control of patients with diabetes: a systematic review and meta-analysis. J Diabetes Investig. 2013;4(5):502-509. doi:10.1111/jdi.12088

11. Hyvärinen K, Salminen A, Salomaa V, Pussinen PJ. Systemic exposure to a common periodontal pathogen and missing teeth are associated with metabolic syndrome. Acta Diabetol. 2015;52(1):179-182. doi:10.1007/s00592-014-0586-y

12. Pink C, Kocher T, Meisel P, et al. Longitudinal effects of systemic inflammation markers on periodontitis. J Clin Periodontol. 2015;42(11):988997. doi:10.1111/jcpe. 12473

13. Giannobile WV. Host-response therapeutics for periodontal diseases. J Periodontol. 2008;79(8 Suppl):1592-1600. doi:10.1902/jop.2008.080174

14. Golub LM, Lee HM, Greenwald RA, et al. A matrix metalloproteinase inhibitor reduces bone-type collagen degradation fragments and specific collagenases in gingival crevicular fluid during adult periodontitis. Inflamm Res. 1997;46(8):310-319. doi:10.1007/s000110050193

15. Golub LM, Lee HM, Ryan ME, Giannobile WV, Payne J, Sorsa T. Tetracyclines inhibit connective tissue breakdown by multiple non-antimicrobial mechanisms. Adv Dent Res. 1998;12(2):12-26. doi:10.1177/08959374980120010501

16. Golub LM, Ramamurthy NS, McNamara TF, Greenwald RA, Rifkin BR. Tetracyclines inhibit connective tissue breakdown: new therapeutic implications for an old family of drugs. Crit Rev Oral Biol Med. 1991;2(3):297-321. doi:10.1177/10454411910020030201

17. Golub LM, Lee HM. Periodontal therapeutics: current host-modulation agents and future directions. Periodontol. 2020;82(1):186-204. doi:10.1111/ prd. 12315

18. Preshaw PM. Host response modulation in periodontics. Periodontol. 2008;48(1):92-110. doi:10.1111/j.1600-0757.2008.00252.x

19. Zhang Y, Golub LM, Johnson F, Wishnia A. pKa, zinc- and serum albumin-binding of curcumin and two novel biologically-active chemicallymodified curcumins. Curr Med Chem. 2012;19(25):4367-4375. doi:10.2174/092986712802884240

20. Zhang Y, Gu Y, Lee HM, et al. Design, synthesis and biological activity of new polyenolic inhibitors of matrix metalloproteinases: a focus on chemically-modified curcumins. Curr Med Chem. 2012;19(25):4348-4358. doi:10.2174/092986712802884295

21. Zhang DW, Fu M, Gao SH, Liu JL. Curcumin and diabetes: a systematic review. Evid Based Complement Alternat Med. $2013 ; 2013: 636053$. doi:10.1155/2013/636053

22. Elburki MS, Rossa C, Guimaraes MR, et al. A novel chemically modified curcumin reduces severity of experimental periodontal disease in rats: initial observations. J Mediators Inflamm. 2014;2014:10. doi:10.1155/2014/959471

23. Elburki MS, Moore DD, Terezakis NG, et al. A novel chemically modified curcumin reduces inflammation-mediated connective tissue breakdown in a rat model of diabetes: periodontal and systemic effects. J Periodontal Res. 2017;52(2):186-200. doi:10.1111/jre.12381

24. Elburki MS, Rossa C Jr, Guimares-Stabili MR, et al. A chemically modified curcumin (CMC 2.24) inhibits nuclear factor kappa B activation and inflammatory bone loss in Murine models of LPS-induced experimental periodontitis and diabetes-associated natural periodontitis. Inflammation. 2017;40(4):1436-1449. doi:10.1007/s10753-017-0587-4

25. Botchkina GI, Zuniga ES, Rowehl RH, et al. Prostate cancer stem cell-targeted efficacy of a new-generation taxoid, SBT-1214 and novel polyenolic zinc-binding curcuminoid, CMC2.24. PLoS One. 2013;8(9):e69884. doi:10.1371/journal.pone.0069884

26. Deng J, Golub LM, Lee HM, et al. Chemically-modified curcumin 2.24: a novel systemic therapy for natural periodontitis in dogs. $J$ Exp Pharmacol. 2020;12:47-60. doi:10.2147/JEP.S236792

27. Wang HH, Lee HM, Raja V, et al. Enhanced efficacy of chemically modified curcumin in experimental periodontitis: systemic implications. $J$ Exp Pharmacol. 2019;11:1-14. doi:10.2147/JEP.S171119 
28. Zhang Y, McClain SA, Lee HM, et al. A novel chemically modified curcumin "Normalizes" wound-healing in rats with experimentally induced type I diabetes: initial studies. J Diabetes Res. 2016;2016:5782904. doi:10.1155/2016/5782904

29. Robinson S, Delongeas J-L, Donald E, et al. A European pharmaceutical company initiative challenging the regulatory requirement for acute toxicity studies in pharmaceutical drug development. Regul Toxicol Pharmacol. 2008;50(3):345-352. doi:10.1016/j.yrtph.2007.11.009

30. de Almeida Brandão D, Spolidorio LC, Johnson F, Golub LM, Guimarães-Stabili MR, Rossa C Jr. Dose-response assessment of chemically modified curcumin in experimental periodontitis. $J$ Periodontol. 2019;90(5):535-545. doi:10.1002/JPER.18-0392

31. Zhang Y. Design, Synthesis and Biological Evaluation of Novel Curcumin Analogues as Inhibitors of Matrix Metalloproteinases and Proinflammatory Cytokines [Thesis]. Stony Brook: Stony Brook University; 2012.

32. Curylofo-Zotti FA, Elburki MS, Oliveira PA, et al. Differential effects of natural curcumin and chemically modified curcumin on inflammation and bone resorption in model of experimental periodontitis. Arch Oral Biol. 2018;91:42-50. doi:10.1016/j.archoralbio.2018.04.007

33. Mallangada NA, Vargas JM, Thomas S, et al. A novel tricarbonylmethane agent (CMC2.24) reduces human pancreatic tumor growth in mice by targeting Ras. Mol Carcinog. 2018;57(9):1130-1143. doi:10.1002/mc.22830

34. Gu Y, Lee HM, Napolitano N, et al. 4-methoxycarbonyl curcumin: a unique inhibitor of both inflammatory mediators and periodontal inflammation. Mediators Inflamm. 2013;2013:329740. doi:10.1155/2013/329740

35. Giknis MLA, Clifford CB. Clinical laboratory parameters for Crl: CD (SD) rats. Wilmington, MA; 2006:18.

36. Shoba G, Joy D, Joseph T, Majeed M, Rajendran R, Srinivas PSSR. Influence of piperine on the pharmacokinetics of curcumin in animals and human volunteers. Planta Med. 1998;64(04):353-356. doi:10.1055/s-2006-957450

37. Lao CD, Ruffin MT, Normolle D, et al. Dose escalation of a curcuminoid formulation. BMC Complement Altern Med. 2006;6(1):1-4. doi:10.1186/ $1472-6882-6-10$

38. Anand P, Kunnumakkara AB, Newman RA, Aggarwal BB. Bioavailability of curcumin: problems and promises. Mol Pharm. 2007;4(6):807-818. doi:10.1021/mp700113r

\section{Publish your work in this journal}

The Journal of Experimental Pharmacology is an international, peer-reviewed, open access journal publishing original research, reports, reviews and commentaries on all areas of laboratory and experimental pharmacology. The manuscript management system is completely online and includes a very quick and fair peer-review system. Visit http://www.dovepress.com/testimonials.php to read real quotes from published authors.

Submit your manuscript here: https://www.dovepress.com/journal-of-experimental-pharmacology-journal 